\title{
INK DYES FOR WASHABLE LEATHERS
}

\author{
ARIFE CANDAŞ ADIGÜZEL ZENGIN ${ }^{1}$, NIMA POURRASOUL SARDROUDI ${ }^{1}$, \\ EYLEM KILIÇ ${ }^{2}$, BEHZAT ORAL B TL SL *1 \\ ${ }^{1}$ Ege University, Engineering Faculty, Leather Engineering Department, Bornova, zmir, 35100, \\ Turkey, +902323114401, *corresponding author: oral.bitlisli@ege.edu.tr \\ ${ }^{2}$ Usak University Material Science and Nanotechnology Engineering, 1 Eylül Campus, 64200, \\ Turkey, E-mail: eylem.kilic@usak.edu.tr
}

\begin{abstract}
Inks, contain pigments or dyes in liquid or paste form, are used to color an image, text, or design. Although some patents describing the ink jet printing methods for textile and leather were found, no report was found addressing the application of ink dyes in leather dying process and determination of washing and other fastness properties. In this study, the potential application of ink dyes in leather industry was investigated as an alternative to conventional dyes for the production of washable leathers in dying process. For this purpose, leather-dyeing recipes were developed by using two different ink dyes and applied at dying process of metis type crust leathers in order to produce washable leathers. The quality performance of dyed leathers were investigated in terms of color measurements, to-and-fro rubbing fastness, crockmeter rubbing fastness, and light fastness characteristics before and after washing leathers in a washing machine under specified conditions according to ISO 15702 standard. The color measurements prior and subsequent to washing process were determined with Minolta CM-3600A spectrophotometer. Toand-fro rubbing, crockmeter and light fastness properties were examined in accordance with ISO 11640, ASTM D5053 and ISO 105-B02 standards respectively. The results of the study showed that ink dyes could be used as a newly adapted dye group and applied successfully in leather dyeing process for the production of washable leather goods.
\end{abstract}

Keywords: washable leathers, ink dyes, color fastness, leather dyeing

\section{INTRODUCTION}

Dyes and pigments offer significant potential for functional and aesthetic design of leather materials. Search for viable alternative leather colorants, which have the potential to develop new creative designs and provide functionality are presently in focus. In this context application of alternative textile dye substances that can offer special effects to leather have been investigated (Şeren, Adıgüzel Zengin, \& Bitlisli, 2013).

During the last decade ink jet printing has made significant progress and expanded their fields of applications. Inks, used in these applications contain pigments or dyes in liquid or paste form, are used to color an image, text, or design. Although some patents describing the ink jet printing methods for textile and leather were found, no report was found addressing the application of ink dyes in leather dying process. In order to ensure the applicability of ink dyes in leather dyeing processes, to develop a leather dyeing recipe suitable for ink dyes, the initial treatment of leather samples with dye and subsequent determination of brightness, colour as well as testing the colour fastness performances are of critical importance.

In this study three types of ink dyes such as dye, pigment and sublimation based ink dyes were applied to crust leathers through newly developed dyeing recipes to investigate whether they can be considered as a new class of dye substance for the leather industry. The qualitative properties and fastness performance of ink-dyed leather were analyzed before and after washing trials. 


\section{MATERIAL AND METHOD}

\section{Material}

In the study, metis type crust leathers were used for the application of the ink dye dispersions and pigments in the dyeing process. Three types of dyes were used in the trials such as pigmented, dye and sublimation based inks. All of them were water based dyes and supplied from Akici Inkjet and Laser Technologies in Istanbul, Turkey.

\section{Experimental}

The dyeing process of the crust leathers was given in Table 1. After drying and mechanical operations, the visual displays of the leathers dyed with pigmented, dye and sublimation based ink dyes were shown in Figure 1.

\section{Dyeing Trials}

Table 1. Dyeing recipe of crust leathers by three type ink dyes

\begin{tabular}{|c|c|c|c|c|c|}
\hline Process* & $\%$ & Material & ${ }^{\circ} \mathrm{C}$ & Time (min) & $\mathrm{pH}$ \\
\hline \multirow[t]{2}{*}{ Re-wetting } & 1000 & Water & $35-40$ & & \\
\hline & 1,5 & $\begin{array}{l}\text { Wetting agent stabile to } \\
\text { electrolytes }\end{array}$ & & & $5.0-5.5$ \\
\hline \multirow[t]{5}{*}{ Dyeing } & $\begin{array}{l}80 \\
x\end{array}$ & $\begin{array}{l}\text { Water } \\
\text { Ink dve }\end{array}$ & $35-40$ & 45 & \\
\hline & 70 & Water & 50 & & \\
\hline & 7 & $\begin{array}{l}\text { Neutral fatliquoring agent with } \\
\text { synthetic emulgators }\end{array}$ & & & \\
\hline & 5 & Synthetic fatliquoring agent & & 45 & \\
\hline & 3 & $\mathrm{HCOOH}$ & & 30 & 3.8 \\
\hline
\end{tabular}

*The dyeing process of the crust leathers were based on dry weight
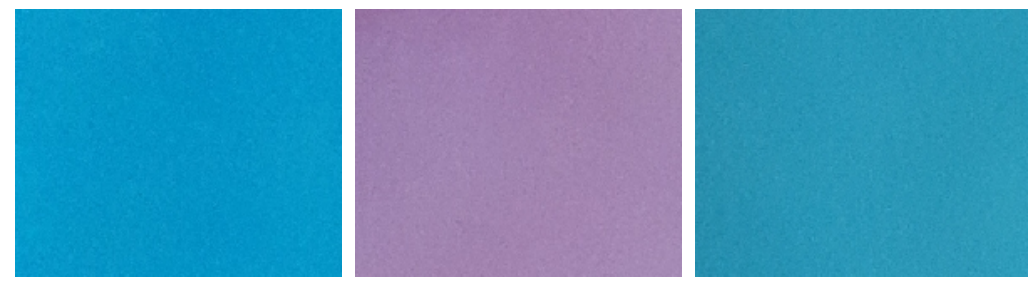

Figure 1 . The leathers dyed with sublimation, pigmented and dye based inks, respectively

\section{Color Measurements}

The color measurements prior and subsequent to washing process were determined with Minolta CM-3600A spectrophotometer (Konica, Japan). The measurements were performed according to the Commission Internationale de l'Eclairage (CIE) Lab color system (McLaren, 1983). Color of samples was assessed performing multiple surface color measurements (minimum 10 measurements) from different regions of the sample, and triplicate experiments were performed. 
ICAMS $2016-6^{\text {th }}$ International Conference on Advanced Materials and Systems

\section{To and Fro Rubbing Fastness}

The rubbing fastness properties of leathers were examined by Bally Finish Tester 9029 according to ISO 11640 standard (100 rubs in dry and 25 rubs in wet) (ISO 11640, 2012). Prior and subsequent to the rubbing tests, color measurements were performed and the changes in color were compared.

\section{Crock-meter Rubbing Fastness}

The crockmeter rubbing fastness of the leathers was performed in accordance with ASTM D5053 standard (ASTM D5053, 2003). The dry and wet rubbing fastness (10 rubs for each) was tested by Atlas CM5 (SDL ATLAS Company, USA) test device. The fabric used in the test was evaluated according to the standard ISO 105-A03 while the leather samples were evaluated as follows; $1=$ Good, 2 = Medium, 3= Poor (ISO 105A03, 1993).

\section{Light Fastness}

The light fastness properties were determined in accordance with the standard of ISO 105-B02 by the Atlas-Xenotest Alpha+ device (Illinois, USA) (ISO 105-B02, 2013). The color change of the leathers was evaluated using gray scale with the standard of ISO 105-A02 (ISO 105-A02, 1993).

\section{Washing Trials}

Washing fastness tests were carried out in accordance with ISO 15702 (ISO 15702, 1998) to determine the color fastness of ink-dyed leathers to washings. Dyed samples were exposed to 30 minutes washing process in a detergent medium $(4 \mathrm{~g} / \mathrm{L})$ using a steel laundry machine at $40^{\circ} \mathrm{C}$ and $40 \mathrm{rpm}$.

\section{RESULTS AND DISCUSSION}

The spectrophotometric color measurements of ink- dyed leathers prior and subsequent to washing are shown in Table 2 and 3. The results were evaluated according to CIE Lab color system and the explanation of the CIE coordinates are as follows: $L^{*}=0$ yields black and $L^{*}=100$ yields white; negative values of $a^{*}$ indicate green, positive values indicate red; negative $b^{*}$ values indicate blue and positive values indicate yellow (Mutlu et al., 2014).

Table 2. Color measurement values of ink dyed leathers before washing

\begin{tabular}{llllllll}
\hline & $\mathrm{L}$ & $\mathrm{a}$ & $\mathrm{b}$ & $\mathrm{dL}$ & $\mathrm{da}$ & $\mathrm{db}$ & $\mathrm{dE}$ \\
\hline Dye based_grain & 68.71 & -26.43 & -13.14 & -30.20 & -26.32 & -12.78 & 42.07 \\
Dye based_suede & 58.80 & -29.56 & -17.38 & -40.11 & -29.45 & -17.02 & 52.62 \\
Sublimation dye_grain & 57.93 & -28.62 & -26.71 & -40.99 & -28.52 & -26.35 & 56.49 \\
Sublimation dye_suede & 61.05 & -24.13 & -14.90 & -37.86 & -24.02 & -14.54 & 47.50 \\
Pigment based_grain & 60.60 & 28.87 & -9.72 & -38.31 & 28.97 & -9.36 & 49.16 \\
Pigment based_suede & 44.54 & 23.99 & -4.95 & -29.65 & 24.07 & -4.68 & 41.52 \\
\hline
\end{tabular}

\footnotetext{
$* \mathrm{~L}, \mathrm{a}, \mathrm{b}$ values of white color as a target given as respectively; $98.92,-0.105,-0.36$
} 
The color measurement values of ink dyed leathers showed that there was a color difference between the grain and suede side of the leathers ( E). Sublimation based dyes resulted similar $L$ values compared to other ink dyed leathers. The values of ' $a$ ' and ' $b$ ' indicated that dye based ink dyed leathers had more green color compared to leathers dyed with sublimation based dyes. The leathers dyed with pigmented based ink dyes had positive a values indicating the red color of the leathers. The negative values of $b$ gave the blue color to the leathers dyed with pigmented based ink dyes that resulted purple colored leathers (Table 2).

Table 3. Color measurement values of ink dyed leathers after washing

\begin{tabular}{llllllll}
\hline & $\mathrm{L}$ & $\mathrm{a}$ & $\mathrm{b}$ & $\mathrm{dL}$ & $\mathrm{da}$ & $\mathrm{db}$ & $\mathrm{dE}$ \\
\hline Dye based_grain & 77.30 & -12.17 & -1.92 & -21.61 & -12.07 & -1.56 & 24.85 \\
Dye based_suede & 71.17 & -17.81 & -5.44 & -27.74 & -17.71 & -5.07 & 33.34 \\
Sublimation dye_grain & 63.01 & -28.25 & -22.52 & -35.90 & -28.15 & -22.15 & 50.75 \\
Sublimation dye_suede & 65.86 & -21.69 & -10.92 & -33.05 & -21.58 & -10.56 & 41.00 \\
Pigment based_grain & 64.70 & 22.41 & -6.40 & -34.21 & 22.51 & -6.04 & 42.93 \\
Pigment based_suede & 66.68 & 11.93 & -3.38 & -32.24 & 12.04 & -3.02 & 34.61 \\
\hline
\end{tabular}

$* \mathrm{~L}, \mathrm{a}, \mathrm{b}$ values of white color as a target given as respectively; $98.92,-0.105,-0.36$

After washing, the brightness of the ink dyed leathers was obtained higher than the brightness values of the leathers before washing. The color difference of the grain and suede side of the leathers was still found ( E). The less affected leather group from the washing treatment was determined as the leathers dyed with sublimation based dyes. The decrease of the negative ' $a$ ' and ' $b$ ' values were the indication of the unfavorable washing effect (Table 3). The to and fro rubbing fastness results of ink dyed leathers are given in Table 4 and 5.

Table 4. To and fro rubbing fastness results of ink dyed leathers before washing

\begin{tabular}{lllll}
\hline & Dry & & Wet & \\
& Felt & Leather & Felt & Leather \\
\hline Dye based & $4 / 5$ & $4 / 5$ & $4 / 5$ & $4 / 5$ \\
Sublimation dye & $4 / 5$ & $4 / 5$ & $4 / 5$ & $4 / 5$ \\
Pigment based & 5 & $4 / 5$ & $4 / 5$ & $4 / 5$ \\
\hline
\end{tabular}

All three groups of ink dyed leathers gave the highest wet/dry rubbing fastness results for the felt and leather examination according to gray scale (Table 4) before washing. The only slight difference was observed for the leathers dyed with pigmented based ink dyes for the dry felt examination.

Table 5. To and fro rubbing fastness results of ink dyed leathers after washing

\begin{tabular}{lllll}
\hline & Dry & & Wet & \\
& Felt & Leather & Felt & Leather \\
\hline Dye based & 5 & $4 / 5$ & $4 / 5$ & $3 / 4$ \\
Sublimation dye & 5 & 5 & 4 & $4 / 5$ \\
Pigment based & 5 & $4 / 5$ & 4 & 4 \\
\hline
\end{tabular}

No difference was observed from the dry to and fro rubbing fastness test results after washing for the ink dyes. However, lower values were obtained from the ink dyed 
ICAMS $2016-6^{\text {th }}$ International Conference on Advanced Materials and Systems

leathers in terms of wet rubbing fastness of leathers especially for dyed based ink dyes, in addition similar results were obtained from the leathers dyed with sublimation based ink dyes (Table 5).

The crockmeter rubbing fastness results of the ink dyed leathers prior and subsequent to washing are given at Table 6 and 7. The dry crockmeter fastness results of the ink dyed leathers were found quite high. Although, wet crockmeter fastness results of the leathers were found lower than the dry crockmeter results, satisfactory fastness results were obtained before and after washing of the leathers.

Table 6. Crockmeter fastness results of ink dyed leathers before washing

\begin{tabular}{lcccc}
\hline & Dry & \multicolumn{3}{c}{ Wet } \\
& Fabric & Leather & Fabric & Leather \\
\hline Dye based & $4 / 5$ & 1 & 3 & 2 \\
Sublimation dye & 4 & 1 & 4 & 2 \\
Pigment based & $4 / 5$ & 1 & $3 / 4$ & 2 \\
\hline
\end{tabular}

The evaluation of the leather for crockmeter; 1 good; 2 medium; 3 poor

Table 7. Crockmeter fastness results of ink dyed leathers after washing

\begin{tabular}{lcccc}
\hline & Dry & \multicolumn{3}{c}{ Wet } \\
& Fabric & Leather & Fabric & Leather \\
\hline Dye based & 5 & 1 & $3 / 4$ & 2 \\
Sublimation dye & $4 / 5$ & 1 & $3 / 4$ & 1 \\
Pigment based & $4 / 5$ & 1 & 4 & 1 \\
\hline
\end{tabular}

The evaluation of the leather for crockmeter; 1 good; 2 medium; 3 poor

The color fastness to machine-washing results of the ink-dyed leathers, are shown in Table 8. Washing fastness results were indicated that the leathers dyed with sublimation based ink dyes had the highest results, however the dye of the leathers dyed with dye based ink dyes was removed. Also, pigmented and sublimation based dyes discolored the fabric.

Table 8. Washing fastness results of ink dyed leathers

\begin{tabular}{llll}
\hline & Fabric & Grain Side & Suede Side \\
\hline Dye based & 1 & 1 & 1 \\
Sublimation dye & 1 & $4 / 5$ & $4 / 5$ \\
Pigment based & 1 & 4 & 4 \\
\hline
\end{tabular}

The lightfastness properties of sublimation and pigmented based ink dyes were found quite high (4/5). This property was also kept after the washing treatment that provides a good opportunity for the production of washable leathers (Table 9). The washing and light fastness properties were correlated for the leathers dyed with dyed based inks. The dye based ink dye was almost removed after the washing process that also affected the lightfastness results. 
Ink Dyes for Washable Leathers

Table 9. Light fastness properties of ink dyed leathers

\begin{tabular}{lcc}
\hline & $\begin{array}{c}\text { Before } \\
\text { Washing }\end{array}$ & $\begin{array}{c}\text { After } \\
\text { Washing }\end{array}$ \\
\hline Dye based & 2 & 1 \\
Sublimation dye & $4 / 5$ & $4 / 5$ \\
Pigment based & $4 / 5$ & $4 / 5$ \\
\hline
\end{tabular}

\section{CONCLUSION}

In this study, the application of ink based pigments/dyes as an alternative dye substance for leather industry was investigated. Three ink dyes such as pigment, sublimation and dye based ink dyes were evaluated within this scope and the results of the study showed that ink dyes especially sublimation based dyes could be used as a newly adapted dye group and applied successfully in leather dyeing process for the production of washable leather goods.

\section{Acknowledgement}

The authors would like to thank to Akici Inkjet and Laser Technologies Company, TR for providing ink dyes and pigments and Turkey Prime Ministry State Planning Organization for the supply of equipments (Project no: 2007 DPT 001).

\section{REFERENCES}

ASTM D5053. (2003). Standard test method for color fastness of crocking leather.

ISO 105-A02. (1993). Textiles-Tests for color fastness-Part A02: Grey scale for assessing change in color.

ISO 105-A03. (1993). Textiles-Tests for color fastness - Part A03: Grey scale for assessing staining.

ISO 105-B02. (2013). Textiles-Tests for color fastness - Part B02: Color fastness to artificial light: Xenon arc fading lamp test.

ISO 11640. (2012). Leather - Tests for colour fastness -Colour fastness to cycles of to-and-fro rubbing.

ISO 15702. (1998). Leather -- Tests for colour fastness -- Colour fastness to machine washing, International Organization for Standardization (ISO).

McLaren, K. (1983), The color science of dyes and pigments, Bristol, UK: Adam Hilger Ltd.

Mutlu, M.M., Crudu, M., Maier, S.S., Deselnicu, D., Albu, L., Gulumser, G. et al. (2014), "Eco-Leather: Properties of Chromium-Free Leathers Produced with Titanium Tanning Materials Obtained from the Wastes of the Metal Industry", Ekoloji, 23(91), 83-90.

Şeren, A., Adıgüzel Zengin, A.C., and Bitlisli, B.O. (2013), "Thermo-chromic Pigments in Leather Finishing", Paper presented at the XXXII. Congress of IULTCS. 